\title{
Uso de bioestimulante na formação de mudas de maracujazeiro amarelo
}

\section{Use of bioestimulant in yellow passion fruit seedlings}

\author{
Márcia de Moraes Echer'; Vandeir Francisco Guimarães²; \\ Cristiani Regina Krieser³; Vânia Márcia Abucarma³; Jeferson Klein ${ }^{4}$; \\ Luciana dos Santos; ${ }^{5}$ Willian Rafael Dallabrida ${ }^{6}$.
}

Resumo

\begin{abstract}
A produção de mudas de alta qualidade torna-se uma estratégia importante para o sucesso de uma cultura. Desta forma, o presente trabalho teve como objetivo avaliar o efeito de diferentes doses de bioestimulante Stimulate ${ }^{\circledR}$ na formação de mudas de maracujazeiro. O experimento foi conduzido em casa de vegetação, em delineamento experimental em blocos casualizados, com parcelas subdivididas no tempo, com seis tratamentos e quatro repetições, sendo cada parcela composta de 24 plantas. Os tratamentos foram constituídos de diferentes doses de bioestimulante: 0 (água destilada), 4, 12, 16 e 20 $\mathrm{mL} \mathrm{kg}^{-1}$ sementes. Foram coletadas duas plantas por parcela aos 15, 22, 29, 36, 43 e 50 dias após a emergência. As características avaliadas foram altura de plantas, área foliar, massa seca de folhas, parte aérea, raízes, massa seca total, razão raiz/parte aérea, taxa de crescimento absoluto e relativo, taxa assimilatória líquida, razão de área foliar e área foliar específica. Verificou-se efeito positivo do bioestimulante sobre a maioria das variáveis avaliadas, em relação à testemunha. Doses entre 4 e $6 \mathrm{~mL}$ de Stimulate ${ }^{\mathrm{kg}} \mathrm{kg}^{-1}$ de sementes promoveram maior equilíbrio entre o sistema radicular e a parte aérea, o que pode favorecer o estabelecimento da muda no campo.
\end{abstract}

Palavras-chave: Maracujá, passiflora, reguladores vegetais, análise de crescimento, propagação

\begin{abstract}
The production of seedlings of high quality becomes an important strategy for the success of a crop. The present research had the objective of evaluating the effect of different bioestimulant doses, Stimulate $\AA$, in the formation of passion fruit seedlings. The experiment was carried out in greenhouse conditions, in randomize complete blocks experimental design with six treatments and four replications, with 24 plants per plots. The treatments were constituted of different bioestimulante doses: 0 (distilled water), 4, 12, 16 and $20 \mathrm{~mL} \mathrm{~kg}^{-1}$ seeds. Plants were collected 15, 22, 29, 36, 43 and 50 days after the emergency. Evaluations were plant height, leaf area, dries mass of leaves, shoot, root and total dry mass; root/shoot relation, absolute and relative growth rate, net assimilate rate, leaf area ratio and specific leaf area. Positive effect of the bioestimulant was verified on most of the appraised variables, in relation to the control. Doses between 4 and $6 \mathrm{~mL}$ of Stimulate ${ }^{\circledR} \mathrm{kg}^{-1}$ of seeds promoted better balance between the root and shoot, which can improve the establishment of the seedlings in the field.
\end{abstract}

Key words: Passion fruit, passiflora, plant growth regulators, plants growth analysis, propagation

1 Eng. Agrônoma, Doutora em Fitotecnia.

2 Prof. Adjunto do Centro de Ciências Agrárias, UNIOESTE- Marechal Cândido Rondon- PR. Rua Pernambuco, 1777, 85960-

000. E-mail: vandeirfg@yahooo.com.br.

3 Acadêmicas de Agronomia/UNIOESTE

${ }^{45}$ Doutorando em Ciências Biológicas/UNESP

6 Mestranda em Horticultura/UNESP

* Autor para correspondência

Recebido para publicação 24/1 1/05 Aprovado em 07/04/06 


\section{Introdução}

O maracujazeiro azedo ou amarelo, Passiflora edulis f. flavicarpa, é a principal Passifloracea cultivada no Brasil e pode ser propagado por via sexual ou assexual (LIMA, 2002). No Brasil e na maioria dos países produtores do maracujá amarelo a produção de mudas é realizada principalmente por sementes, embora também possam ser utilizadas a enxertia e estaquia.

A produção de mudas constitui-se em uma das etapas mais importantes do sistema produtivo, influenciando diretamente no desempenho da planta. Assim o sucesso da instalação de um pomar de frutíferas é garantido pelo uso de mudas de alta qualidade, homogêneas, de rápida formação e com precocidade na produção (NATALE et al., 2004).

A semeadura em recipientes é atualmente a forma mais empregada na produção de mudas de maracujazeiro. As vantagens do sistema de produção de mudas em recipientes são múltiplas e justificam plenamente sua adoção. Dentre estas se podem destacar maior precocidade, menor possibilidade de contaminação com fitopatógenos, melhor controle ambiental, melhor aproveitamento das sementes e da área de produção de mudas e menor estresse no transplante. Estas vantagens se manifestam durante a produção das mudas e também no transplante para área de produção. A redução do tempo de produção de mudas é um fator primordial, visto que quanto mais rápido a muda é produzida menor custos são despendidos com insumos e mão-de-obra (MINAMI et al., 1995).

Neste sentido, a utilização de reguladores vegetais se torna uma alternativa interessante. Com a descoberta dos efeitos dos reguladores vegetais sobre as plantas cultivadas e os benefícios promovidos por estas substâncias, muitos compostos e combinações desses produtos têm sido pesquisados com a finalidade de resolver problemas do sistema de produção e melhorar qualitativa e quantitativamente a produtividade (CASTRO; VIEIRA, 2003).
O emprego de reguladores vegetais como técnica agronômica para se otimizar a produção em diversas culturas tem crescido nos últimos anos. Weaver (1972) descreve que os órgãos de uma planta são alterados morfologicamente pela aplicação de reguladores vegetais. Desta forma, o crescimento e o desenvolvimento das plantas são promovidos ou inibidos, influenciando ou modificando os processos fisiológicos de modo a controlar a atividade meristemática.

Dentre as substâncias consideradas hormônios vegetais estão as auxinas, as citocininas e as giberilinas. O primeiro grupo de hormônios vegetais descoberto pelo homem foi o das auxinas, que são responsáveis pelo crescimento das plantas, e influenciam diretamente nos mecanismos de expansão celular. Quanto às citocininas, essas foram descobertas em estudos relacionados ao processo de divisão celular. Além dessa atividade fundamental ao desenvolvimento do vegetal, outras atividades estão ligadas a esse hormônio, como a inibição da senescência foliar, a mobilização de nutrientes, a dominância apical, a formação e a atividade dos meristemas apicais, o desenvolvimento floral, a germinação de sementes e a quebra de dormência de gemas. Mais recentemente foram descobertas outras funções para as citocininas, atuando em processos de desenvolvimento das plantas regulado pela luz, incluindo a diferenciação dos cloroplastos, o desenvolvimento do metabolismo autotrófico e a expansão de folhas e cotilédones (TAIZ; ZEIGLER, 2004). Os estudos com as giberelinas se iniciaram em 1930 e se intensificaram a partir de 1950. A função desse grupo de hormônios está associada à promoção do crescimento caulinar, dentre outros efeitos fisiológicos. Plantas submetidas a aplicações de giberelinas podem ser induzidas a obter um maior crescimento na sua estatura.

Devido aos efeitos adicionais que existem entre os grupos de reguladores vegetais que promovem o crescimento e desenvolvimento dos vegetais, é crescente a utilização de produtos denominados bioestimulantes, que Castro e Vieira (2001) definem 
como sendo a mistura de dois ou mais reguladores vegetais com outras substâncias (aminoácidos, nutrientes, vitaminas, etc). Dentre os benefícios ocasionados pela utilização dos bioestimulantes, podese citar o incremento do crescimento e do desenvolvimento vegetal, estimulando a divisão celular, a diferenciação e o alongamento das células.

Tecchio et al. (2005) relatam que em videira, cultivar 'Tieta', a aplicação do bioestimulante Stimulate ${ }^{\circledR}$ em diferentes doses, associado com Natura'l Óleo, diretamente no cacho, resultou em maior massa fresca dos cachos, sendo a resposta atribuída à maior fixação de bagos na ráquis e maior massa do engaço. Foram observados efeitos adversos do bioestimulante resultando em decréscimo do diâmetro do pedicelo e atraso na maturação, além do surgimento de manchas marrons nos bagos.

Atualmente, é crescente o número de estudos realizados para avaliar interferências dos reguladores vegetais sobre diversas culturas. Assim, cada vez mais as pesquisas têm apontado para a utilização de produtos que apresentem em sua composição mais de um regulador vegetal, como é o caso dos bioestimulantes. Neste contexto, o presente trabalho teve como objetivo avaliar o efeito de diferentes doses do bioestimulante Stimulate ${ }^{\circledR}$ na formação de mudas de maracujazeiro em tubetes.

\section{Material de Métodos}

O experimento foi conduzido em ambiente protegido na Área de Horticultura e Cultivo Protegido, pertencente ao Núcleo de Estações Experimentais da UNIOESTE, Campus de Marechal Cândido Rondon - PR, de setembro a dezembro de 2004.

O delineamento experimental foi em blocos ao acaso, com seis tratamentos e quatro repetições, sendo cada parcela composta de 24 plantas. Os tratamentos foram as seguintes doses de bioestimulante: 0 (água destilada), 4, 12, 16 e $20 \mathrm{~mL}$ por $1 \mathrm{~kg}$ sementes.

O bioestimulante utilizado no tratamento das sementes foi o Stimulate ${ }^{\circledR}$, um produto comercial líquido (Stoller do Brasil LDTA), composto por três reguladores vegetais: $90 \mathrm{mg} \mathrm{L}^{-1}$ de cinetina (citocinina), $50 \mathrm{mg} \mathrm{L}^{-1}$ de ácido giberélico (giberelina), $50 \mathrm{mg} \mathrm{L}^{-1}$ de ácido indolbutírico (auxina) e 99,981\% de ingredientes inertes.

O bioestimulante ou água destilada foi aplicado diretamente sobre as sementes com o auxílio de uma pipeta graduada, na ocasião da semeadura. Para tal, as sementes foram acondicionadas em sacos plásticos inflados com ar e agitados vigorosamente durante dois minutos, para uniformizar a distribuição do produto sobre toda a massa de sementes. Em seguida, as sementes foram colocadas para secar à sombra durante uma hora, sendo posteriormente realiza a semeadura (CASTRO; VIEIRA, 2001).

A semeadura foi realizada em 15 de setembro de 2004, utilizando-se tubetes de $300 \mathrm{~mL}$ e como substrato uma mistura de terra, esterco de curral curtido e casca de arroz carbonizada, em proporções iguais. Para cada $\mathrm{m}^{3}$ da mistura foram aplicados 2 $\mathrm{kg}$ de calcário dolomítico, $1 \mathrm{~kg}$ de superfosfato simples e $0,5 \mathrm{~kg}$ de cloreto de potássio. Foram colocadas três sementes por tubete, sendo feito o desbaste após a germinação, deixando-se apenas uma plântula por tubete. Estes foram mantidos em condições de casa de vegetação e a irrigação realizada sempre que necessária.

Durante o período de condução do experimento foram realizadas 3 adubações foliares com uma solução na concentração de $3,0 \mathrm{~g} \mathrm{~L}^{-1}$ com a seguinte composição: nitrogênio (15\%), $\mathrm{P}_{2} \mathrm{O}_{5}(15 \%), \mathrm{K}_{2} \mathrm{O}$ (20\%), Ca (1,1\%), S (4\%), Mg (0,4\%), B (0,05\%), $\mathrm{Cu}(0,05 \%), \mathrm{Fe}(0,1 \%), \mathrm{Mn}(0,03 \%)$, e Zn $(0,05 \%)$.

Realizaram-se seis coletas de plantas durante o período de desenvolvimento das mudas, aos 15, 22, 29, 36, 43 e 50 dias após a emergência (DAE), amostrando-se duas plantas por parcela, escolhidas aleatoriamente. Após cada coleta, as plantas foram levadas ao laboratório onde determinou-se a altura de plantas $(\mathrm{cm})$, medida do colo até o ápice da planta (H), com auxílio de uma régua. Posteriormente as 
plantas foram seccionadas separando as folhas, os pecíolos e as raízes. Procedeu-se então a mensuração da área foliar (AF) com medidor portátil de área foliar (A 100-ADC). Logo em seguida, as diferentes partes da planta (folha, raiz e caule + pecíolo) foram acondicionadas em sacos de papel e secas em estufas de circulação forçada de ar a $65^{\circ} \mathrm{C} \pm 5^{\circ} \mathrm{C}$, até atingirem massa constante. Determinou-se, com uma balança de precisão, a massa seca de folhas (MSF), massa seca de caule mais pecíolo (MSCP) e massa seca de raiz (MSR). Calculou-se então a massa seca da parte aérea (MSPA), massa seca total (MST) e a razão entre a massa seca da raiz e a massa seca da parte aérea (RRPA).

Utilizando o programa computacional ANACRES, segundo Portes e Castro (1991), ajustou-se os dados de altura de plantas, massa seca dos diferentes órgãos e área foliar em função do tempo (DAE), para as diferentes doses de bioestimulante. A altura das plantas foi ajustada em um modelo linear, enquanto os dados de massa seca e área foliar foram ajustados em um modelo exponencial quadrático, sendo os ajustes significativos pelo teste $\mathrm{F}(\mathrm{P}<0,05)$. A partir dos dados de massa seca e área foliar foram calculadas a taxa de crescimento absoluto (TCA), taxa de crescimento relativo (TCR), taxa assimilatória líquida (TAL), razão de área foliar (RAF) e área foliar específica (AFE).

Os dados da última coleta de plantas foram submetidos à análise de variância e análise de regressão para estudar os efeitos das doses de bioestimulante em cada variável.

\section{Resultados e Discussão}

Analisando as Figuras 1, 2 e 3, relativas às variáveis biométricas e de crescimento, em função do desenvolvimento das mudas de maracujá amarelo, nota-se que os tratamentos com bioestimulante resultaram em efeitos positivos na maioria das características estudadas, destacando-se o incremento em área foliar (Figura 1a). Nos primeiros 29 dias as mudas de todos os tratamentos apresentaram área foliar semelhante. A partir deste período houve um maior incremento em área foliar em função da aplicação do bioestimulante, destacando-se as doses de 4 e $12 \mathrm{~mL} \mathrm{Kg}^{-1}$ de sementes.

O incremento observado em área foliar das mudas de maracujá amarelo, em resposta à aplicação de 8 e $12 \mathrm{~mL}$ de bioestimulante por $\mathrm{kg}$ de semente, resultou em superioridade na área foliar específica (AFE) para estes tratamentos, a partir de $29 \mathrm{DAE}$ (Figura 1c). Segundo Benincasa (1988) a AFE relaciona a superfície da folha (componente morfológico) com a massa seca da folha (componente anatômico) estimando a composição interna da folha (número ou tamanho de células do mesófilo foliar). A AFE então, indica a espessura foliar.

A Figura 1d mostra o incremento linear para a altura de plantas em função do tempo até 50 DAE, não ficando evidente a resposta da aplicação de bioestimulante para esta variável. Aos 50 DAE, as mudas apresentavam aproximadamente $12 \mathrm{~cm}$ de altura.

Na Figura 2 observa-se a resposta positiva do bioestimulante, quando comparado à testemunha, com incremento em massa seca da parte aérea e raízes, durante o desenvolvimento das mudas de maracujazeiro amarelo. Aos 50 DAE, é menor o acúmulo de massa seca na parte aérea e raízes das plantas que não receberam aplicação de bioestimulante via semente (testemunha). Para a massa seca de raízes a dose de $4 \mathrm{~mL}$ por $\mathrm{Kg}$ de semente mostrou mais eficiência. Este desenvolvimento se acentua após a terceira avaliação, ou seja, a partir dos 30 dias após a emergência (Figura 2b). Para as demais doses a diferença em massa seca de raiz se iniciou após 43 dias da emergência.

A razão raiz/parte aérea mostrou queda nos primeiros 30 dias de desenvolvimento da muda após a emergência, estabilizando nas demais avaliações. A partir de 30 DAE destacou-se, para esta variável, as mudas que foram tratadas com $4 \mathrm{~mL}$ de bioestimulante por $\mathrm{kg}$ de sementes. $\mathrm{O}$ aumento da 

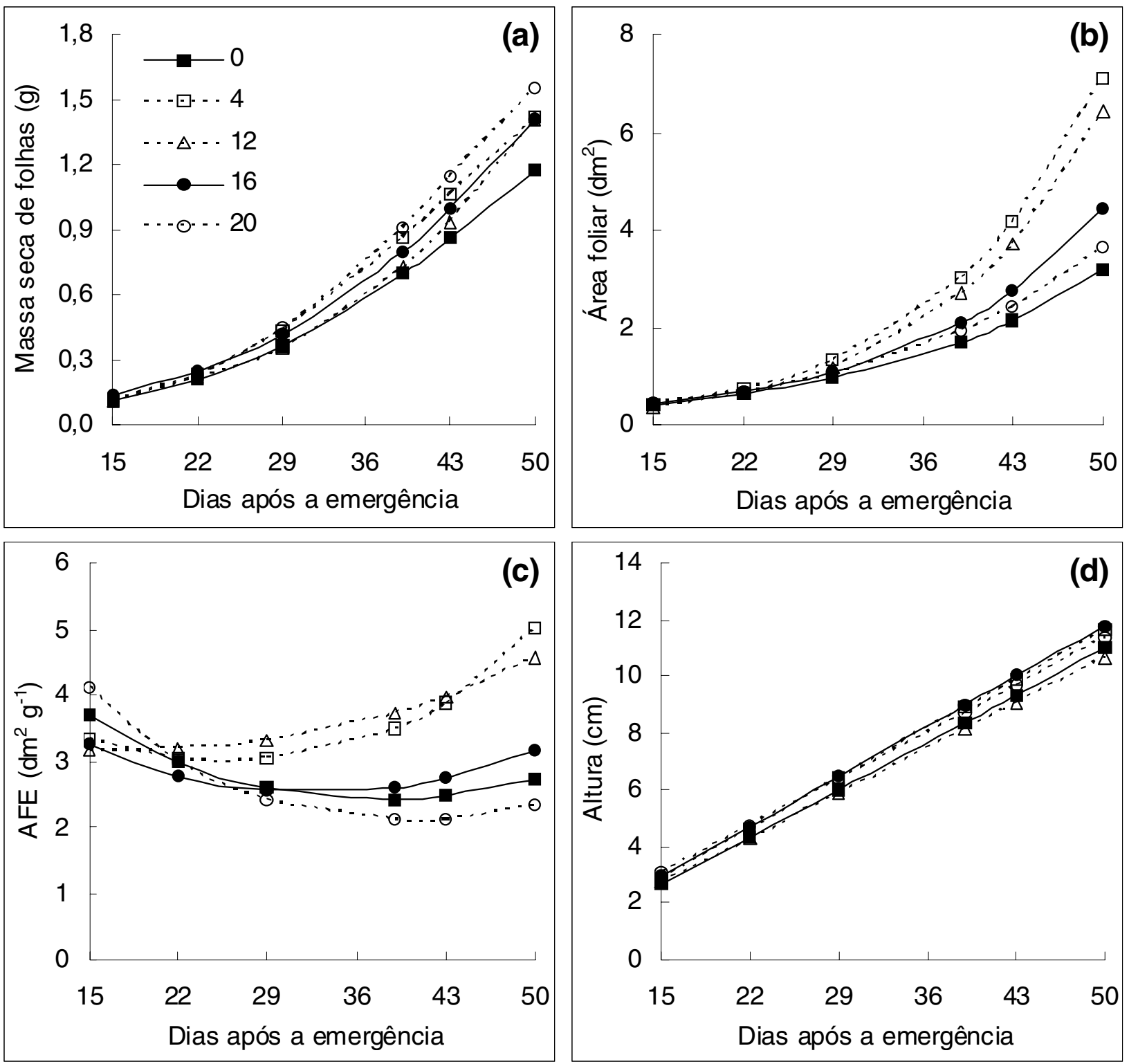

Figura 1. Área foliar (a), massa seca de folhas (b), área foliar específica (AFE) (c) e altura (d) de mudas de maracujazeiro em função dos dias após a emergência e da aplicação de diferentes doses do bioestimulante Stimulate®, nas sementes.

razão raiz/parte aérea é desejável para se obter mudas de qualidade, principalmente no pegamento após o transplantio no campo.

O crescimento das mudas em função do tempo é demonstrado na Figura 3. Menor velocidade de crescimento é verificada nas mudas provenientes de sementes que não receberam tratamento com bioestimulante, principalmente a partir de $36 \mathrm{DAE}$ (Figura 3a), momento em que as mudas deveriam apresentar alta taxa de acúmulo de massa seca e rápido crescimento. Desta forma, verifica-se superioridade na taxa de crescimento absoluto das mudas em resposta à aplicação de bioestimulante. Esta resposta é interessante visando obtenção de mudas em menor tempo, sendo um dos objetivos da produção de mudas de qualidade, que reflete em economia de área e insumos para o produtor, possibilitando uma rápida implantação do pomar (NATALE et al, 2004) e rápido retorno financeiro. 

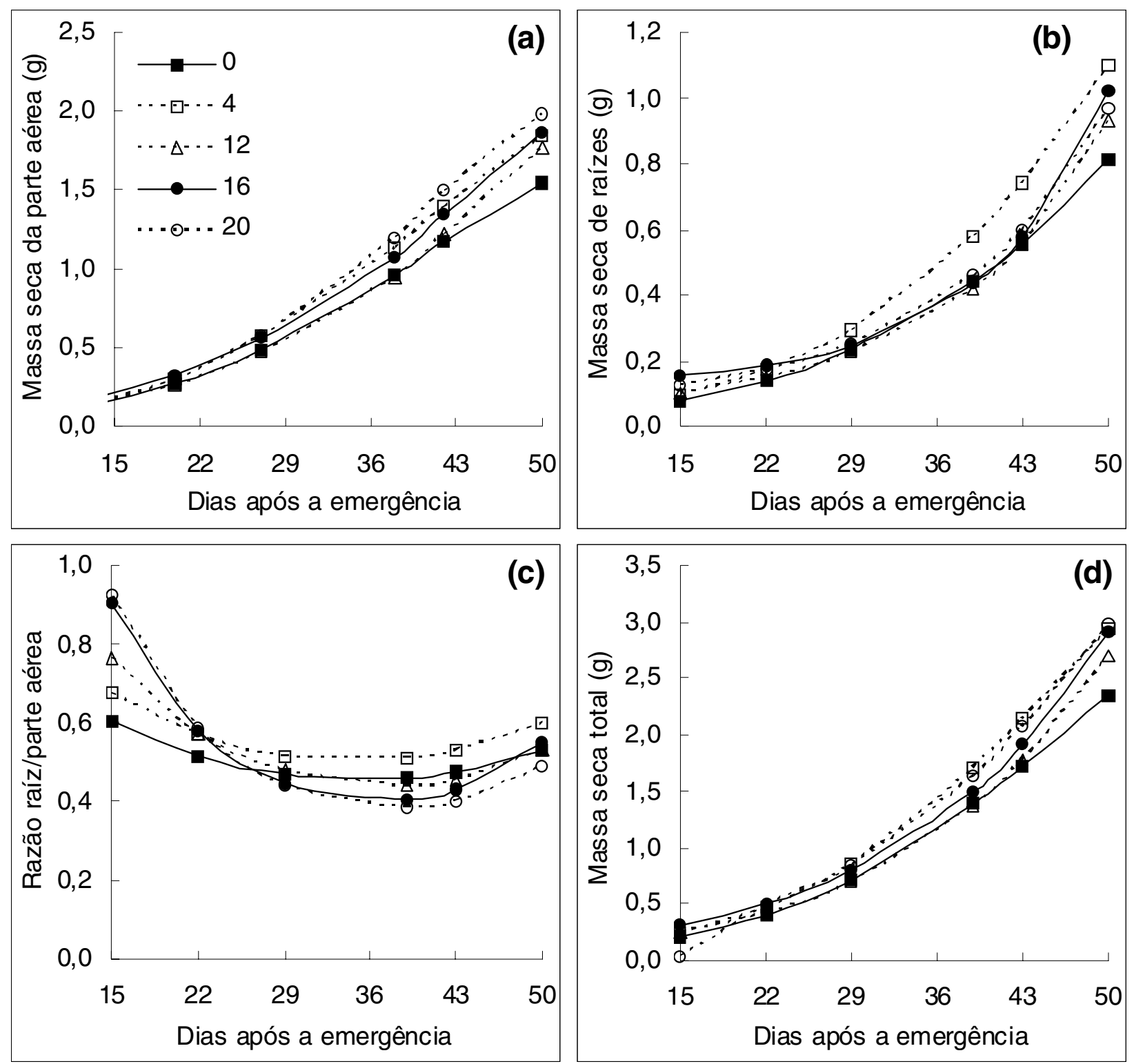

Figura 2. Massa seca da parte aérea (a), massa seca de raízes (b), razão raiz/parte aérea (c) e massa seca total (d) de mudas de maracujazeiro em função dos dias após a emergência (DAE) e da aplicação de diferentes doses do bioestimulante Stimulate ${ }^{\circledR}$, via sementes.

A taxa de crescimento relativo das mudas decresceu para todos os tratamentos em função do desenvolvimento das mesmas (Figura 3b). Fato explicado pelo gasto de energia na manutenção dos tecidos, que aumenta com o ganho de massa seca das plantas (BENINCASA, 1988).

$\mathrm{O}$ incremento em área foliar observado nas mudas que receberam doses de 4 e $12 \mathrm{~mL}$ de bioestimulante por $\mathrm{kg}$ de semente, antes da semeadura (Figura 1b) resultaram em mudas com maior razão de área foliar (RAF), a partir de 29 DAE, quando comparada à testemunha e aos demais tratamentos. A maior RAF refletiu em menor taxa assimilatória líquida (TAL) para as mudas tratadas com 4 e $12 \mathrm{~mL}$ de bioestimulante por kg de semente, reflexo provavelmente devido ao maior sombreamento das folhas que resultou em menor produção de massa seca por unidade de área foliar. Contudo, é possível notar que a redução na TAL não foi prejudicial ao desenvolvimento das mudas, tendo 

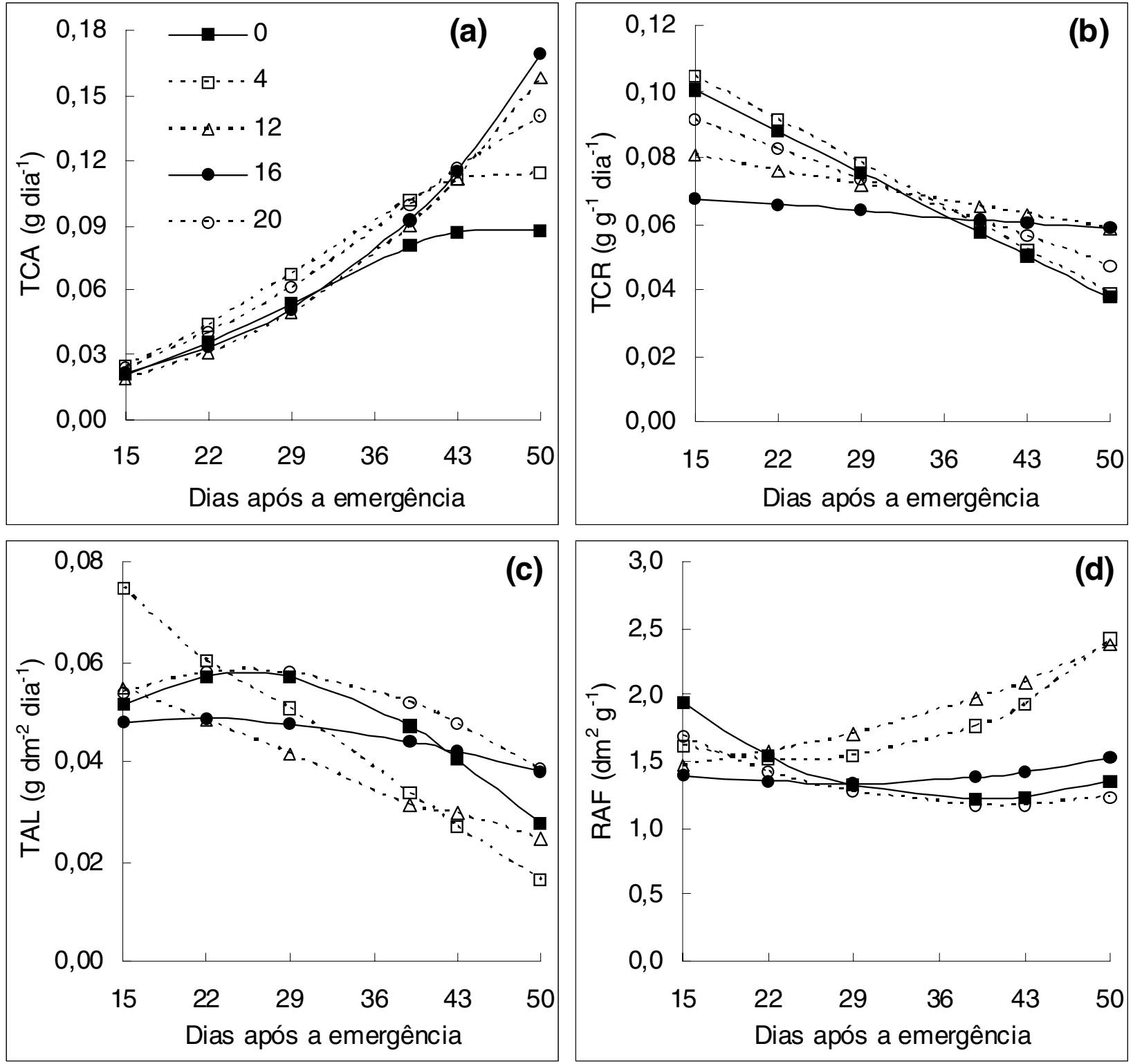

Figura 3. Taxa de crescimento absoluto (TCA) (a), taxa de crescimento relativo (TCA) (b), taxa assimilatória líquida (TAL) (c) e razão de área foliar (RAF) (d), de mudas de maracujazeiro em função dos dias de após a emergência (DAE) e da aplicação de diferentes doses do bioestimulante Stimulate®, via sementes.

estas mantido a fotossíntese líquida positiva durante este período de crescimento.

Na Figura 4 são apresentadas as respostas de área foliar, massa seca de folhas, parte aérea e raízes de mudas de maracujá ao tratamento com diferentes doses de bioestimulante, aos 50 DAE. As equações ajustadas para estas variáveis demonstram o efeito do bioestimulante, afetando positivamente o acúmulo de massa seca nestes órgãos, bem como de área foliar.
Para área foliar e massa seca de raízes, doses entre 4 e $6 \mathrm{~mL}$ de bioestimulante por $\mathrm{kg}$ de sementes seriam recomendáveis, enquanto que para massa seca de folhas e da parte aérea, houve comportamento linear crescente em resposta às doses de bioestimulante aplicadas. Segundo Taiz e Zeiger (2004) o balanço ideal para o crescimento dos diferentes órgãos vegetais é variável, podendo, uma determinada concentração endógena, favorecer o crescimento de um órgão e inibir o crescimento de outro. 

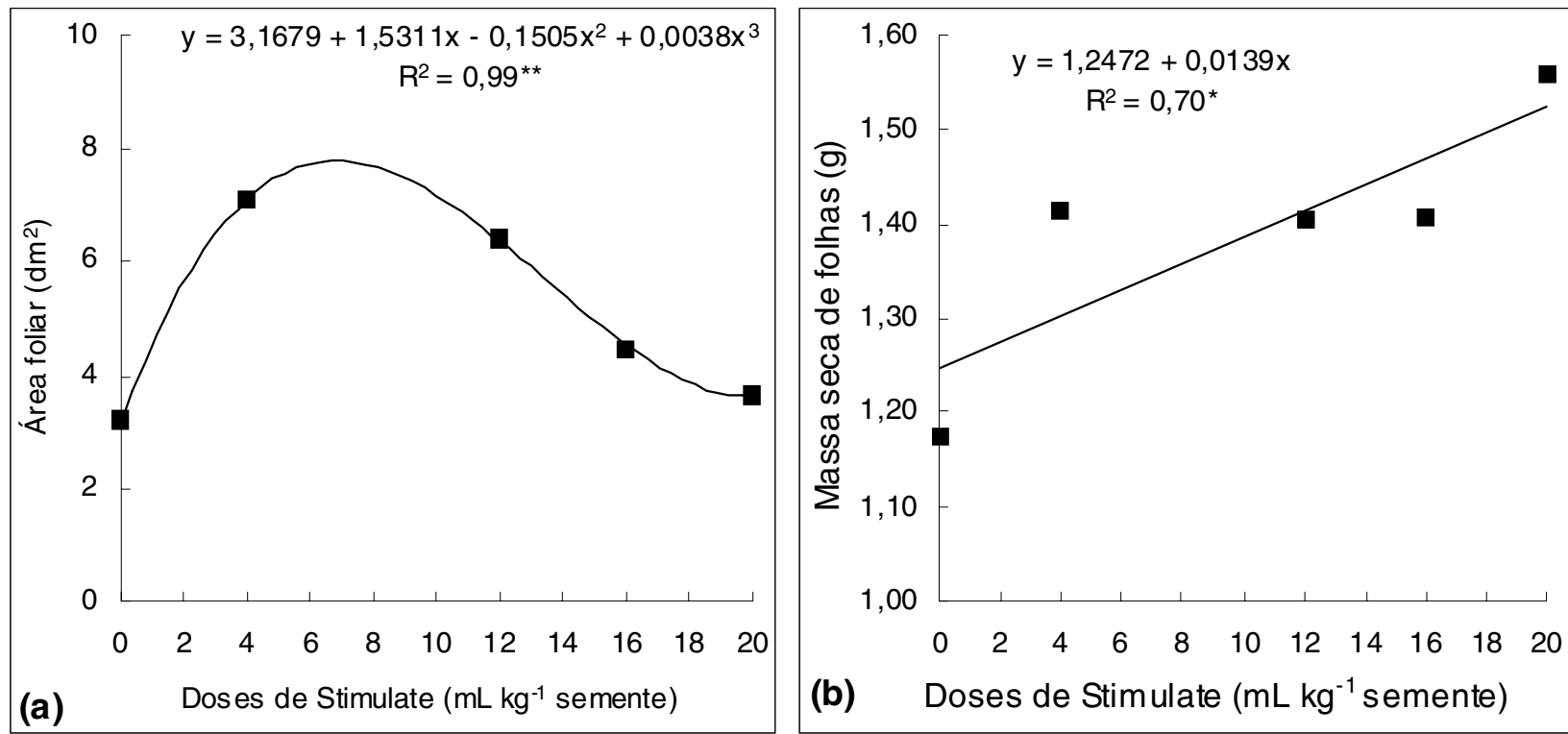

(b) Doses de Stimulate ( $\mathrm{mL} \mathrm{kg}^{-1}$ semente)
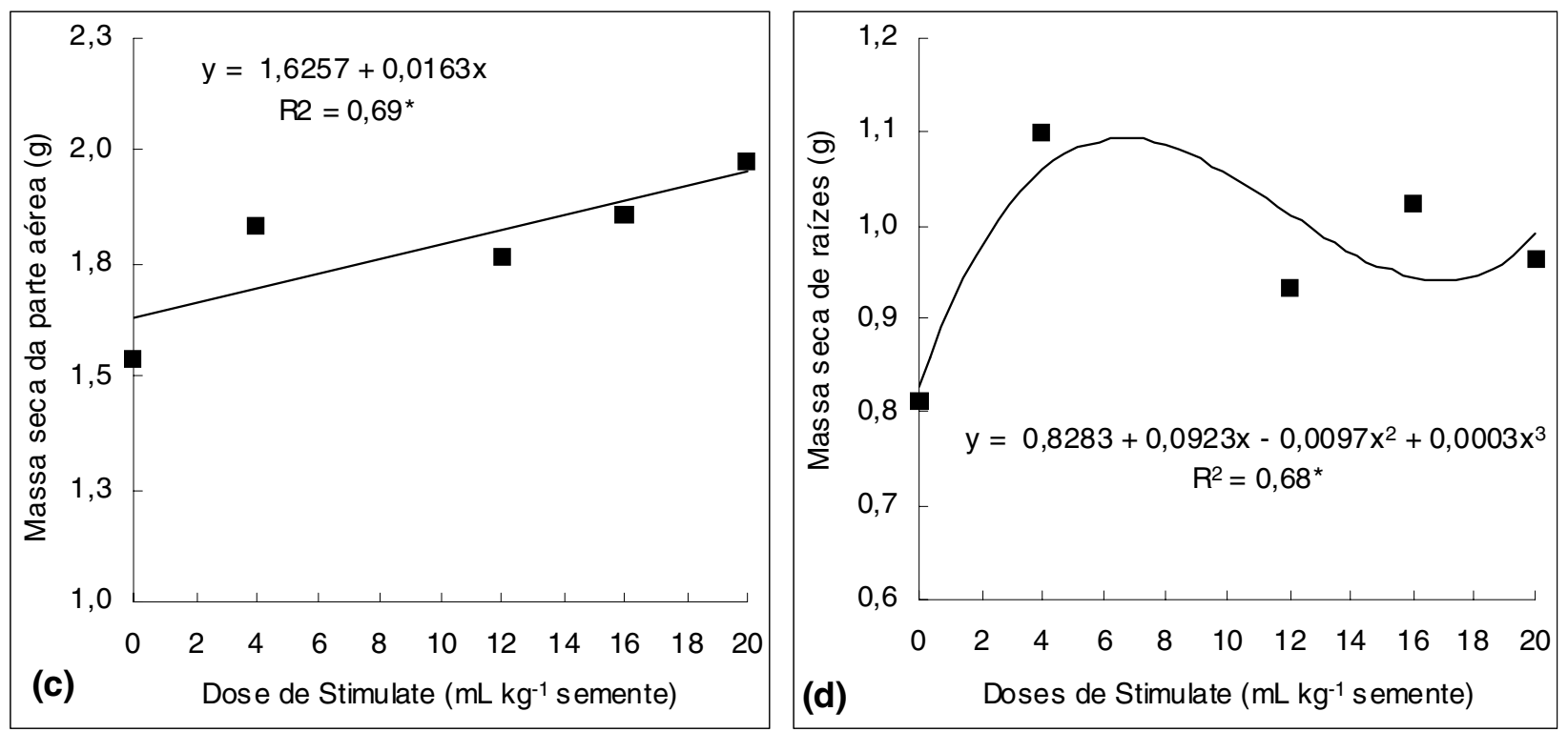

Figura 4. Área foliar (a), massa seca de folhas(b), massa seca da parte aérea (c) e massa seca de raízes(d), de mudas de maracujazeiro, aos 50 dias após a emergência, em resposta à aplicação de diferentes doses do bioestimulante Stimulate ${ }^{\circledR}$, via sementes. *Significativo pelo teste $\mathrm{T}$ de Student $(\mathrm{P}<0,05)$. **Significativo pelo teste $\mathrm{T}$ de Student $(\mathrm{P}<0,01)$.

Na produção de mudas de alta qualidade buscase um menor tempo de formação e um equilíbrio entre parte aérea e raiz, resultante de um sistema radicular bem desenvolvido, que apresenta alta correlação com a taxa de pegamento de mudas a campo, após o transplante. Segundo Verdial et al. (2000) o tamanho da muda influencia o desenvolvimento inicial das mesmas, sendo que mudas maiores tendem a formar plantas mais desenvolvidas após o transplante. 


\section{Conclusões}

Considerando os aspectos já discutidos e as doses de bioestimulante testadas, a dose de $4 \mathrm{~mL}$ por $\mathrm{kg}$ de sementes destaca-se por proporcionar maior acúmulo de massa seca, com área foliar e sistema radicular bem desenvolvido, expresso pela razão raiz/parte aérea maior que 0,6 .

\section{Agradecimentos}

Os autores agradecem à Universidade Estadual do Paraná, Campus de Marechal Cândido Rondon $\mathrm{PR}$, pela infraestrutura necessária à condução do trabalho e à Stoller do Brasil LTDA, por fornecer o bioestimulante.

\section{Referências}

BENINCASA, M. M. P. Análise de crescimento de plantas: noções básicas. Jaboticabal: FUNEP, 1988.

CASTRO, P. R E.; VIEIRA, E L. Ação de bioestimulante na cultura do feijoeiro. In: FANCELLI, A. L.; DOURADO NETO, V. Feijão irrigado: tecnologia e produtividade. Piracicaba: ESALQ, 2003.

CASTRO, P. R. E.; VIEIRA, E. L. Aplicações de reguladores vegetais na agricultura tropical. Guaíba: Agropecuária, 2001.
LIMA, A. A. Maracujá produção: aspectos técnicos. Brasília: Embrapa Informações Tecnológicas, 2002.

MINAMI, K.; TESSARIOLI NETO, J.; PENTEADO, S. R.; ESCARPARI FILHO, J. A. Produção de mudas de alta qualidade em horticultura. São Paulo: T.A. Queiroz, 1995.

NATALE, W.; PRADO, R. M.; LEAL, R, M.; FRANCO, C. F. Efeitos da aplicação de zinco no desenvolvimento, no estado nutricional e na produção de matéria seca de mudas de maracujazeiro. Revista Brasileira de fruticultura, Jaboticabal, v.26, n.2, p.310-314, Ago. 2004.

PORTES, T. A.; CASTRO, L. G. Análise de crescimento de plantas: um programa auxiliar. Revista Brasileira de Fisiologia Vegetal, Londrina, v.3, n.1, p.53-56, 1991.

TAIZ, L.; ZEIGER, E. Fisiologia vegetal. 3.ed. Porto Alegre: Artmed, 2004.

WEAVER, R. J. Plant growth substances in agriculture. San Francisco: W.H. Freeman, 1972.

TECCHIO, M. A.; PAIOLI-PIRES, E. J.; RODRIGUES, J. D.; VIEIRA, C. R. Y.I.; TERRA, M. M.; BOTELHO, R. V. Aplicação de bioestimulante nas características ampelométricas da infrutescência da videira 'Tieta'. Revista Brasileira de Fruticultura, Cruz Das Almas, v.27, n.2, p.300-303, 2005.

VERDIAL, M. F.; LIMA, M. S.; TESSARIOLI-NETO, J.; DIAS, C. T. S.; BARBANO, M. T. Métodos de formação de mudas de maracujazeiro amarelo. Scientia Agrícola, Piracicaba, v.57, n.4, p.795-798, 2000. 
